\title{
MOdELAGEM (MATEMÁTICA) E MODELAGEM NA EDUCAÇÃO: REFLEXOS NA E DA FORMAÇÃO CONTINUADA
}

\author{
MODELLING (MATHEMATICS) AND MODELACIÓN IN EDUCATION: REFLECTIONS ON AND CONTINUING
} TRAINING

\author{
MODELACIÓN (MATEMÁTICA) Y MODELACIÓN EN LA EDUCACIÓN: REFLEJOS EN LA FORMACIÓN \\ CONTINUADA
}

\author{
BONOTTO, Danusa de Lara 1 \\ SCHELLER, Morgana ${ }^{2}$ \\ LIMA, Valderez Marina do Rosário ${ }^{3}$
}

\begin{abstract}
RESUMO
Este artigo relata a experiência do desenvolvimento de uma tarefa de Modelagem (Matemática) realizada com um grupo de professores de Matemática e sua projeção para a sala de aula a partir dos reflexos na e da formação continuada. Decorrente das reflexões na formação, a tarefa desencadeou novas atividades investigativas e favoreceu a inserção da Modelagem na sala de aula para explorar dois conceitos destaques da Matemática: razão e proporcionalidade por meio do conceito de densidade. Os resultados indicam a avaliação positiva referente à tarefa desenvolvida e projeção de inserção de novas práticas de Modelagem (Matemática) pelos docentes à ação docente, ampliando assim a utilização da Modelagem na Educação no fazer do professor. No entanto, assinalam preocupação com o cumprimento das prescrições, dentre essas, os conteúdos programáticos que constam na matriz curricular de Matemática. Em relação aos estudantes que vivenciaram a tarefa implementada por uma das professoras, estes (re)organizaram as representações textualizadas inicialmente e significaram o conceito de densidade ao expressarem, verbalmente, o modelo matemático. O fizeram para realizar seu cálculo e ao utilizar o conceito para realizar argumentações durante o desenvolvimento da tarefa.
\end{abstract}

Palavras-chave: Professor que ensina Matemática. Formação continuada de professores. Razão e proporção.

\section{ABSTRACT}

This article reports an experience of the development of a task of Modeling (Mathematics) and its projection to the classroom from the reflexes in and the continued formation. From the reflections in the training, the task triggered new research activities and favored the insertion of Modeling in the classroom to explore two main concepts of Mathematics: reason and proportionality through the concept of density. The results indicate the positive evaluation regarding the task developed and projection of the insertion of new practices of Modeling (Mathematics) by the teachers to the teaching action, thus increasing the use of Modeling in Education in the teacher's doing.However, they indicate concern about the fulfillment of the prescriptions, among them, the programmatic contents that are included in the Mathematics curriculum matrix. In relation to the students who experienced the task implemented by one of the teachers, they (re) organized the representations initially textualized and signified the concept of density by verbally expressing the mathematical model. They did so to perform their calculation and to use the concept to make arguments during the development of the task.

Keywords: Teacher who teaches Mathematics. Continuing education of teachers. Reason and proportion.

\section{RESUMEN}

Este artículo relata una experiencia del desarrollo de una tarea de Modelación (Matemática) y su proyección para el aula a partir de los reflejos en y de la formación continuada. A partir de las reflexiones en la formación, la tarea desencadenó nuevas actividades investigativas y favoreció la inserción del Modelaje en el aula para explorar dos conceptos destaques de la

\footnotetext{
1 Universidade Federal da Fronteira Sul - Campus Cerro Largo-Brasil

${ }^{2}$ Instituto Federal Catarinense - Campus Rio do Sul-SC-Brasil

3Pontifícia Universidade Católica do Rio Grande do Sul-Brasil
} 
Matemática: razón y proporcionalidad por medio del concepto de densidad. Los resultados indican la evaluación positiva referente a la tarea desarrollada y proyección de inserción de nuevas prácticas de Modelado (Matemática) por los docentes a la acción docente, ampliando así la utilización de Modelado en la Educación en el hacer del profesor. Sin embargo, señalan preocupación por el cumplimiento de las prescripciones, entre ellas, los contenidos de la matriz curricular de Matemáticas. En cuanto a los estudiantes que vivenciaron la tarea hecha por una de las profesoras, éstos (re) organizaron las representaciones iniciales y significaron el concepto de densidad al expresar, verbalmente, el modelo matemático. Lo hicieron para ejecutar su cálculo y al usar el concepto para hacer argumentaciones en el momento del desarrollo de latarea.

Palabras clave: Profesor que enseña Matemáticas. Formación de profesores. Razón y proporción.

\section{INTRODUÇÃO}

Este estudo trata sobre os fundamentos da Modelagem Matemática (MM) na perspectiva da Educação Matemática e da Formação Continuada de Professores, e foi desenvolvido no contexto de um projeto de extensão, no qual os participantes são professores de Matemática da Educação Básica vinculados à rede pública de ensino. O projeto é desenvolvido desde o ano de 2010 por professores de uma universidade pública do sul do Brasil.

A concepção de formação continuada do projeto é a perspectiva de Imbernón (2010, p. 115), que a concebe "[...] como toda intervenção que provoca mudanças no comportamento, na informação, nos conhecimentos, na compreensão e nas atitudes dos professores em exercício". Ademais, o autor defende a constituição de espaços de formação continuada que favoreçam: a reflexão individual e coletiva na, sobre e para a prática/ação do professor; a recuperação da autonomia docente; a importância do trabalho em equipe; a consideração do contexto político e social como elemento imprescindível, visto que o desenvolvimento humano sempre tem lugar em um contexto social e histórico determinado, não sendo possível, portanto, separar a formação do professor de seu contexto de trabalho (SCHÖN, 1995, 2000; ALARCÃO, 2010; CONTRERAS, 2002; GÓMEZ 1995; NÓVOA, 1995).

Por coadunar com essas ideias, a partir dos problemas apresentados pelos professores participantes nos encontros de formação, como a falta de interesse dos estudantes e a dificuldade de dar sentido à matemática ensinada na escola, optou-se, no ano de 2015, pelo estudo dos pressupostos da Modelagem na perspectiva da Educação Matemática. Para tal, os professores vivenciaram, na formação continuada, a realização de tarefas fundamentadas nos princípios dessa tendência da Educação Matemática. Na sequência, as tarefas foram adaptadas e desenvolvidas pelos participantes da formação em seu ambiente de trabalho, a sala de aula. Para isso, consideraram um conteúdo específico e o nível de escolaridade dos estudantes. Ao final, ocorreu a socialização do que foi desenvolvido com os estudantes nos encontros de formação, com o objetivo de realizar uma avaliação do processo vivenciado.

A partir dessas considerações, o presente trabalho objetiva relatar a realização de uma das tarefas desenvolvidas na formação continuada, envolvendo o tema 'embalagens', o qual desencadeou como tema subsequente o conceito de densidade e, a partir deste, o planejamento de uma nova tarefa de Modelagem e sua implementação na sala de aula. 
Buscando situar a concepção teórica empírica que norteia a formação destaca-se, na perspectiva da Educação Matemática, a concepção de Biembengut $(2014 ; 2016)$. Para a autora, a Modelagem (Matemática) "[...] é um método para solucionar alguma situação-problema ou para compreender um fenômeno utilizando-se de alguma teoria (matemática)" (BIEMBENGUT, 2016, p. 98). Quando concebida como um "método de ensino com pesquisa nos limites e espaços escolares, em qualquer disciplina e fase de escolaridade" (p. 171), a autora denomina de Modelagem na EducaçãoModelação:

\begin{abstract}
[...] o objetivo de quem faz Modelagem (Matemática) é estabelecer um modelo (matemático) de uma situação-problema para então resolvê-la, entende-la ou ainda modificá-la se necessário. Isto é, o objetivo é essencialmente, de fazer pesquisa. No tempo em que é objetivo na Modelaçãopromover conhecimento ao estudante em qualquer período de escolaridade, e ensiná-lo a fazer pesquisa nessa estrutura escolar, isto é: no espaço físico e no período concernente a este propósito. (BIEMBENGUT, 2016, p. 175).
\end{abstract}

Desse modo, a Modelagem na Educação é um método que faz uso da essência da MM para o ensino e aprendizagem (da Matemática). O propósito em utilizar a MM no ensino é muito mais do que ensinar conceitos matemáticos, é "levar os estudantes [...] a pesquisar; condição não frequente no dia a dia em sala de aula" (BIEMBENGUT, 2016, p. 177). Com esse intuito, seus procedimentos são agrupados em três fases: 1) percepção e apreensão - envolve reconhecimento da situação-problema e familiarização sobre o assunto a ser modelado; 2) compreensãoe explicitação - envolve a formulação do problema, do modelo (matemático) e sua resolução; 3) significação e expressão - ocorre a interpretação da solução do modelo e sua validação, bem como a expressão do processo de modelagem.

Por meio da Modelagem na Educação é possível ensinar Matemática de modo integrado às outras disciplinas do currículo. Portanto, sua utilização no ensino favorece, além do estudo dos conteúdos matemáticos, a discussão de temas provenientes de outras áreas do conhecimento.

Para Bonotto e Lara (2013), na formação continuada os fundamentos da MM e da Modelagem na Educação têm sido abordados numa modalidade de formação pautada na racionalidade técnica, em cursos de curta duração (presenciais ou a distância) ou em cursos de especialização e/ou mestrado. As autoras destacam que as ações e os espaços proporcionados pelas pesquisas podem influenciar a prática do professor, entretanto, questionam se o modelo de formação continuada apresentado nas pesquisas proporciona, de fato, condições para que os professores utilizem a MM com os estudantes, visto que os espaços de formação são constituídos para a realização das pesquisas (dissertação e tese) e não há menção de prosseguimento da formação continuada e de acompanhamento do professor. Dentre as pesquisas realizadas, tem-se os estudos realizados em contextos de formação inicial e continuada de professores, como o de Barbosa (2004), Dias (2005), Oliveira (2010), Chaves (2012), Luna (2012), Bisognin e Bisognin (2012), Scheller, Bonotto e Biembengut (2015) e Bonotto e Lima (2016).

Os resultados desses estudos convergem para o entendimento acerca da necessidade de potencializar experiências com Modelagem aos professores, de modo que estes sintam-se encorajados a integrar a Modelagem à prática docente. Diante do exposto, tornam-se necessários estudos envolvendo MM e formação continuada de professores a fim de compreender a vivência do processo 
de Modelagem pelo professor e a adaptação e implementação do processo na sala de aula, conforme Scheller, Bonotto e Biembengut (2015) sugerem. Sugere-se, ainda, compreender em que medida a participação em ações de formação continuada pode promover a transformação do agir docente.

Com o propósito de relatar a experiência do desenvolvimento de uma tarefa de Modelagem (Matemática) e sua projeção para a sala de aula a partir dos reflexos na e da formação continuada, organizou-se este texto da seguinte forma: inicialmente, apresenta-se o espaço reflexivo constituído por meio da formação continuada; a seguir, retrata-se a proposta de Modelagem (Matemática) realizada com os professores na formação continuada e o contexto do surgimento do conceito de densidade; na sequência, apresenta-se e discute-se a proposta planejada e implementada por uma professora participante da formação continuada e, por fim, são apresentadas as considerações sobre o trabalho realizado.

\section{O GRUPO DE PROFESSORES DE MATEMÁTICA}

O projeto de extensão proposto por professores de uma universidade federal localizada no interior do Rio Grande do Sul (RS) e que ampara a ação de formação continuada relatada neste trabalho teve início no ano de 2010. Tal projeto objetiva o envolvimento dos professores participantes em um processo interativo e reflexivo na busca pela autonomia docente, por meio da pesquisa da própria prática e da atualização profissional. No ano de 2015, participaram do grupo dezesseis professores $^{4}$ que lecionam Matemática na Educação Básica na região noroeste do Estado. Os encontros do grupo aconteceram, mensalmente, na universidade, com duração aproximada de três horas. Tais encontros foram gravados em áudio e posteriormente transcritos para análise do processo de formação.

Ademais, adotou-se, na formação, a escrita de diários, os quais funcionaram como instrumento de reflexão da ação e desenvolvimento profissional do professor, conforme Porlán e Martin (1997), Zabalza (2004) e Alarcão (2010) apontam. Todos os professores participantes da formação foram convidados a escrever diários, entretanto, somente sete realizaram a escrita dos diários de: (i) encontros de formação; (ii) planejamento; (iii) implementação das tarefas de Modelagem desenvolvidas com estudantes da Educação Básica.

Neste artigo, apresenta-se o desenvolvimento de uma tarefa de Modelagem (Matemática) realizada com os professores participantes do grupo, nos encontros de abril e maio de 2015. A partir da realização dessa tarefa surgiu o conceito de densidade, desencadeador da realização de uma nova proposta de Modelagem na Educação, a qual foi planejada e implementada com doze estudantes do sétimo ano do Ensino Fundamental por uma das professoras participantes do grupo. Para textualizar este relato, utilizou-se a transcrição do áudio dos encontros de formação 5 e o diário de aplicação da

\footnotetext{
${ }_{4}^{4}$ Os professoresparticipantes do grupo, quando referenciados neste texto, são identificados por letras a fim de preservar suas identidades.

${ }^{5}$ As vozes dos professores participantes da formação são reconstituídas por meio do áudio dos encontros.
} 
tarefa de Modelagem escrito pela referida professora, bem como os registros escritos produzidos pelos estudantes 6 durante o desenvolvimento da proposta.

\section{A TAREFA DE MODELAGEM COM OS PROFESSORES PARTICIPANTES DO GRUPO: COMO TUDO COMEÇOU}

A fim de proporcionar a vivência do processo de MM aos professores participantes da formação continuada e projetar a Modelagem na Educação para sua prática docente, propôs-se a realização da tarefa de Modelagem envolvendo o tema 'embalagens'. Também, por meio da realização dessa tarefa, buscou-se discutir, com os professores, a possibilidade de seu desenvolvimento em diferentes níveis de ensino, considerando a realização de adaptações de acordo com o objetivo do professor e o contexto específico do seu trabalho, como o nível de ensino dos estudantes, o conteúdo programático a ser abordado e a possibilidade de desenvolver estudos extraclasse.

A tarefa de Modelagem em questão, desenvolvida pela formadora com os professores em formação, teve como referência a tarefa esquematizada por Biembengut e Hein (2003) e o experimento 'caixa de papel', disponível no portal da coleção Matemática Multimídia (http://m3.ime.unicamp.br/recursos/1367), que contém recursos educacionais em formatos digitais desenvolvidos pela UNICAMP. Seu desenvolvimento seguiu as etapas propostas por Biembengut (2014), descritas anteriormente.

Na primeira etapa, Percepção e apreensão, os professores foram convidados pela professora formadora a discutir, em grupos, três questões referentes ao tema proposto: 1) $O$ que podemos discutir, considerando a temática 'embalagens', para o ensino e aprendizagem de matemática? 2) Você já usou esse tema para trabalhar algum conteúdo com seus alunos? Se sim, como? 3) O que podemos sugerir para os alunos investigarem sobre esse tema?

As discussões referentes à temática para o ensino e a aprendizagem de Matemática, expressas pelos professores, centraram-se em geometria para abordagem de: planificação das embalagens e diferentes formas geométricas, cálculo da área e do volume, elementos de poliedros, unidades de medida, razão e proporção e estudo das frações.

Em relação às possibilidades de investigação, os professores apontaram: observação de diferentes embalagens para o mesmo produto e explicação da mudança no formato de algumas embalagens ao longo do desenvolvimento industrial, por exemplo, do óleo de cozinha; questões referentes à capacidade da embalagem, quantidade de material utilizada em sua fabricação, tempo de decomposição da embalagem dependendo do material que é utilizado em sua fabricação, o padrão no formato das embalagens e o estudo da relação custo benefício; exploração de diferenças entre peso líquido e peso bruto e problemas referentes ao empilhamento e transporte das embalagens.

\footnotetext{
${ }^{6}$ Os estudantes da professora que implementou a tarefa de Modelagem na Educação são referenciados por letras, a fim de preservar suas identidades.
}

Reflexão e Ação [ISSN 1982-9949]. Santa Cruz do Sul, v. 28, n. 1, p. 235-253, jan./abr. 2020.

https://online.unisc.br/seer/index.php/reflex/index 
$\mathrm{Na}$ etapa de compreensão e explicitação, após a ambientação e discussão do tema, o problema proposto aos professores em formação foi: Dada uma folha A4, de medidas $3021 \mathrm{~cm}$, qual a medida de ' $x$ ' para que a caixa sem tampa, obtida pela dobradura dos cantos, tenha o maior volume possivel?

Fig. 1 - Exemplo de possibilidade de construção da caixa solicitada.

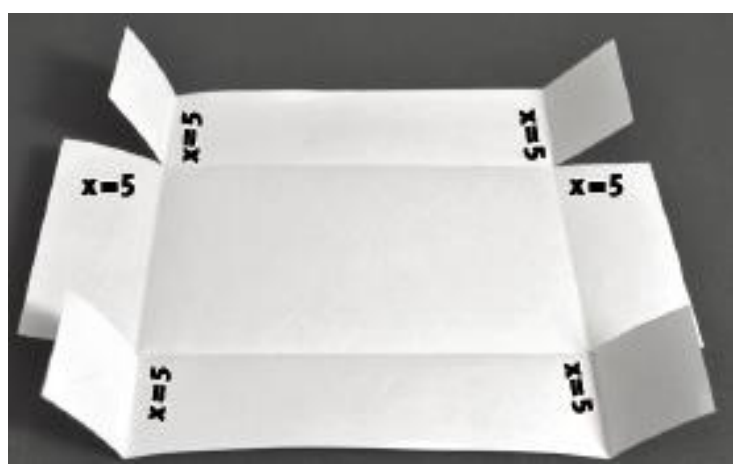

Fonte: http://m3.ime.unicamp.br/recursos/1367

Os professores, de posse de folhas, tesouras e réguas para confeccionar várias caixas, realizaram, inicialmente, a tarefa proposta sem a realização de cálculos numéricos. $O$ apontamento da caixa de maior volume deveria ser acompanhado de justificativa por escrito, sendo várias apresentadas pelos professores, dentre elas:

A de medida 5, porque o espaço interno ficou maior. (Áudio encontro de Abril, 2015, Prof. H).

A de $6 \mathrm{~cm}$, porque é mais alta. (Áudio encontro de Abril, 2015, Prof. F).

A de $3 \mathrm{~cm}$, porque tem o fundo grande. (Áudio encontro de Abril, 2015, Prof. A).

Diante disso, a professora formadora inseriu questionamentos:

Ao comparar as caixas, como saber qual é a que representa o maior volume? Como saber se não existe uma caixa com maior volume que não está entre as que foram construídas por vocês? (Áudio encontro de Abril, 2015, Prof. formadora).

Dentre as sugestões, destacam-se:

Usar a fórmula do volume V=a.b.c. (Áudio encontro de Abril, 2015, prof. B).

Atribuir valores para a altura e testar o volume com cada uma delas. (Áudio encontro de Abril, 2015, Prof. R).

Realizar cálculos aproximados com os décimos. (Áudio encontro de Abril, 2015, Prof. S).

Dentre as estratégias apresentadas pelos professores, sobressaiu-se a utilização de tratamentos realizados no registro numérico. Embora os professores tenham apresentado, anteriormente, possibilidade de utilização de 'fórmula' para o cálculo do volume, as expressões 
algébrica e gráfica do modelo não foram apresentadas por nenhum grupo como modelo para solução do problema proposto. Todavia, perceberam-se tentativas de extrapolar a representação numérica e determinar um padrão na realização dos cálculos, como expressa uma das professoras:

Olha, eu fiz uma com um quadrado maior, outra com um menor e a extremidade pra mim, pra colocar na minha cabeça uma lógica (...) mas quando a gente começou a colocar os valores aqui não fechou (...) foi assim até um determinado ponto, mas de um ponto em diante começou a diminuir de novo. (Áudio encontro de Abril, 2015, Prof. A).

Já na terceira etapa, Significação e expressão, a partir da atividade desenvolvida e da constatação de que os grupos não expressaram o modelo usando as representações algébrica e gráfica, foi proposto, pela professora formadora aos professores, a organização dos dados obtidos em uma planilha e a construção da representação gráfica do volume em função da medida da altura, em malha quadriculada. Assim, obteve-se um modelo gráfico considerando o contexto apresentado na situação problema e, em seguida, sua representação algébrica, dada por, $V(x)=(30-2 x)(21-2 x) x=630 x-102 x^{2}+4 x^{3}, \quad x \in R, 0<x<10,5$. A representação algébrica $\mathrm{e}$ a validação do modelo foram mediadas pela professora formadora. Para tal, utilizou-se o cálculo da derivada e a determinação do máximo da função, encontrando o valor de $x \cong 4,1 \mathrm{~cm}\left(V=1144 \mathrm{~cm}^{3}\right)$ validando, destarte, os resultados obtidos experimentalmente durante a construção das caixas.

\section{O SURGIMENTO DO CONCEITO DE DENSIDADE}

Durante a realização da tarefa, após a construção das caixas e considerando o objetivo de adaptar a tarefa para desenvolvê-la em diferentes níveis de ensino, a professora formadora questionou os professores sobre a possibilidade de desenvolver a atividade nos Anos Finais do Ensino Fundamental, considerando o fato de que os estudantes dessa etapa de escolaridade ainda não operam o cálculo de volume. Em resposta, uma das professoras participantes sugeriu colocar 'alguma coisa' (água - mas a caixa é de papel, farinha, areia, açúcar e sagu) dentro das caixas, já que as medidas de volume e capacidade são ${ }^{7}$ equivalentes. A partir desse momento, a decisão dos professores em formação foi de, no encontro seguinte, fazer uso de dois produtos diferentes e uma balança para a resolução do problema, ou seja, investigar qual das caixas comportava a maior quantidade de algum produto (essa seria, então, a caixa com maior volume).

A experimentação realizada pelos professores originou dados sobre a massa dos produtos. Assim, o problema gerado envolveu o conceito de densidade, já que a quantidade de farinha que a caixa comportava era diferente da quantidade de sagu. Tal fato causou, inicialmente, certo 'desconforto' aos professores, já que a densidade é um conceito abordado na disciplina de ciências, segundo eles.

\footnotetext{
${ }^{7} \mathrm{~A}$ capacidade refere-se à quantidade de armazenamento interno de um recipiente. $\mathrm{O}$ volume refere-se ao espaço ocupado por esse recipiente.
} 
A densidade é a quantidade de massa que cabe, se fizermos um quadradinho de um $\mathrm{cm}$ é a quantidade de massa que cabe de qualquer matéria dentro daquele cm cúbico, se tu colocar água dentro daquele um cm cúbico só vai caber 1 grama de água aqui, agora se colocar sagu ali vai caber diferente (...). Então tem que cuidar pra gente não sair muito da matemática por que se tu vai trabalhar isso, tu tem que saber as ciências. Mas olha a discussão que surge, essa ciência aí é do nono ano, segundo grau, e tem que ser a ciência do sexto ano do sétimo ano. (Áudio encontro abril, 2015, Prof. E).

Esse desconforto surge em virtude de a professora em formação perceber a possibilidade de extrapolar conceitos trabalhados na disciplina de Matemática. Além disso, ela percebe o conceito de densidade como não pertinente à tarefa do professor de matemática ou como possibilidade de trabalho em um campo de risco provocado pela falta de domínio do conteúdo. Ela também justifica que a abordagem do cálculo do volume (sexto ano em Matemática) e a abordagem do conceito de densidade (nono ano em Ciências) ocorrem em períodos de formação distintos. Dessa forma, haveria um 'descompasso' entre os conteúdos abordados em diferentes anos escolares. Esse fato denota a forte relação do professor com o cumprimento dos conteúdos programáticos prescritos na matriz curricular (por vezes fragmentado) e é identificado por Silveira e Caldeira (2012) como uma resistência à prática de Modelagem em sala de aula.

Em momento algum surgiu, explicitamente, o conceito de densidade como uma razão constante envolvendo as grandezas massa e volume, onde tal conceito poderia ser explorado com os estudantes em conjunto com outros conteúdos, quais sejam: razão, proporcionalidade e noção de função linear. Quer dizer, resultaria em um trabalho interdisciplinar em que a matemática estaria auxiliando na compreensão de um conceito que, geralmente, é abordado em Ciências. Nesse sentido, nos encontros seguintes a professora formadora direcionou as discussões de modo que as professoras percebessem as possíveis relações entre esses conceitos (razão, proporcionalidade e densidade), propondo ao grupo a tarefa de explorar os conteúdos de razão e proporção por meio do conceito de densidade, envolvendo os fundamentos da Modelagem na Educação.

\section{A PROPOSTA DE MODELAGEM (MATEMÁtICA) NA SALA DE AULA E AS PERCEPÇÕES dOS ENVOLVIDOS}

A Metodologia Comunicativo-Crítica (MCC), desenvolvida por pesquisadores do CREA - Centro Especial de Investigação em Teorias e Práticas Superadoras de Desigualdades, da Universidade de Barcelona, na Espanha, caracteriza-se por ser ontologicamente comunicativa, pois a realidade é construída pelos significados que as pessoas the atribuem ao interagirem, por meio da comunicação; por ser epistemologicamente dialógica, pois o conhecimento científico é construído pelo diálogo entre as pessoas que investigam e as pessoas investigadas, em condições de igualdade. 
$\mathrm{Na}$ fase de percepção e apreensão, a prof. $L$ trabalhou a questão referente ao vazamento do petróleo na Bacia de Campos, no Rio de Janeiro, por meio de um vídeo8. Seu objetivo, ao utilizar o recurso, foi problematizar a temática que seria explorada, bem como os conceitos de densidade, razão e proporcionalidade. A partir disso, ela buscou identificar os conhecimentos dos estudantes sobre a temática, por meio do questionamento:

Você já se perguntou por que o petróleo fica na superfície da água? (Diário de aplicação da tarefa de modelagem, prof. L, 2015).

As primeiras manifestações dos estudantes estavam focalizadas na poluição ambiental referente ao vazamento do petróleo. Então, a prof. $L$ solicitou que eles observassem o comportamento do petróleo, convidando-os a assistir novamente o vídeo. Segundo ela, os estudantes, rapidamente, perceberam que:

[...] o petróleo não se misturou com a água, ficou em cima. (Diário de aplicação da tarefa de modelagem, prof. L, 2015).

A partir das ideias iniciais dos estudantes a professora propôs a realização de um experimento que ilustrasse o acontecimento visualizado no vídeo. A Figura 2 ilustra a realização do experimento.

Fig. 2 - llustração do experimento realizado pelos envolvidos na tarefa de Modelagem.

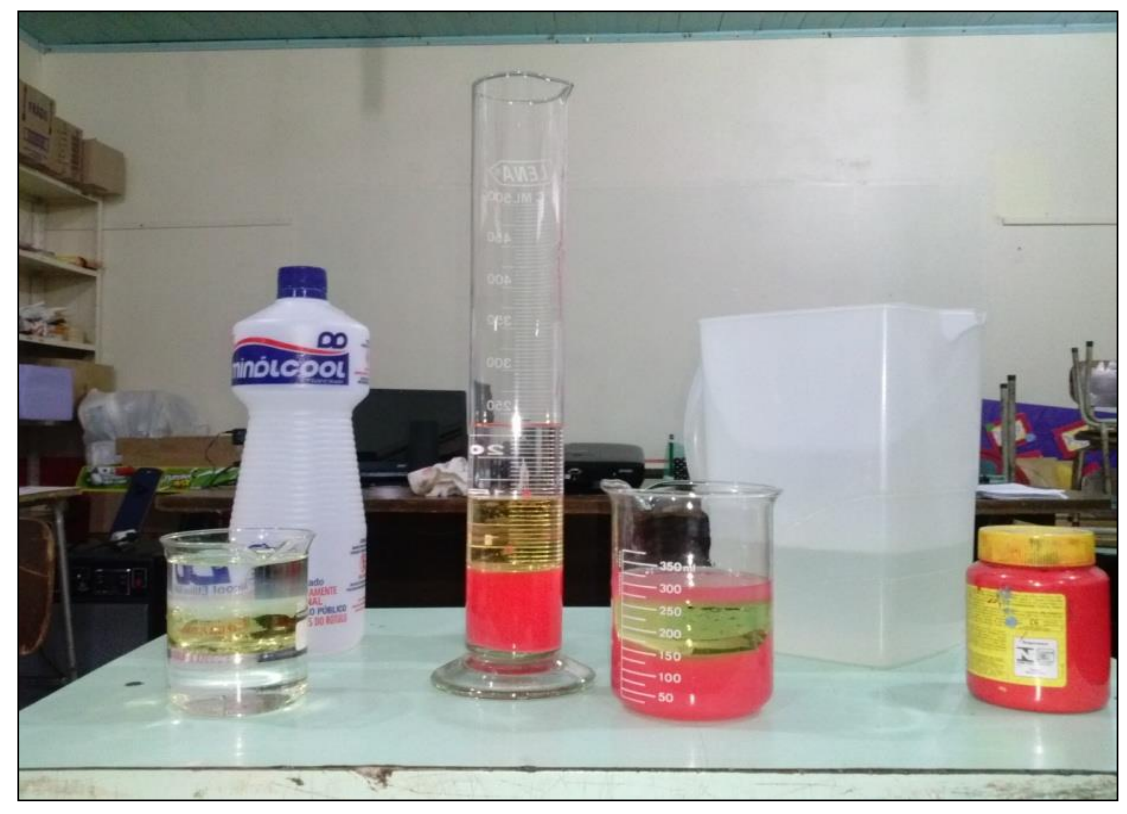

Fonte: Registro fotográfico da professora L (2015).

Para a realização do experimento, a professora $L$ utilizou como materiais: um recipiente alto de vidro, uma medida de óleo de cozinha, uma medida de água, uma medida de álcool etílico e tinta guache. Com eles à disposição da turma, a professora $L$ orientou os estudantes quanto aos

\footnotetext{
${ }_{8}^{8}$ Disponível em: https://www.youtube.com/watch?v=xEW85V9K9ck.
} 
procedimentos de realização do experimento, tais como: adição de uma 'gotinha' de tinta guache à água, tornando a água colorida; introdução da água colorida no recipiente de vidro; adição lenta de óleo pela lateral do recipiente; adição do álcool da mesma maneira; repouso das substâncias por alguns minutos. Após a realização do experimento, os estudantes foram orientados a registrar, por escrito, justificativas para: a) Observe o comportamento dos líquidos. O que aconteceu? b) Tente justificar por que isso aconteceu. A esse respeito, a professora expressa, em seu diário de implementação da tarefa de Modelagem, que:

Eles adoraram a ideia, os alunos que eu não esperava se disponibilizaram a realizar o procedimento. Acharam bonito, a forma em que ficaram dispostos os líquidos, mas não concluíram direito o porquê daquela disposição dos líquidos, alguns ficavam na dúvida de que mesmo o álcool não ia se misturar com a água. (Diário de aplicação da tarefa de modelagem, prof. L, 2015).

Percebe-se que a professora $L$ inicia o seu planejamento buscando as representações, textualizadas pelos estudantes, acerca do tema que seria estudado. Na sequência, ela realiza o experimento a fim de que os discentes confrontassem essas representações com o resultado do experimento e buscassem justificativas para tentar explicar o porquê da disposição dos líquidos. Ou seja, a partir das representações textualizadas pelos estudantes iniciou-se um processo de construção de novos argumentos, o qual, segundo Moraes (2012), faz parte de uma educação que prima pela pesquisa.

Os registros escritos dos estudantes evidenciam que, na percepção deles, a maneira como os líquidos foram colocados no recipiente e os componentes de cada um deles influenciam no resultado do experimento:

Porque se fosse derramado tudo ligeiro iria se misturar. Assim, colocamos um pela lateral do vidro. Até parece inacreditável. (Registro escrito do estudante F).

Por causa dos componentes que há em cada um. (Registro escrito do estudante C).

Porque o óleo foi colocado antes do álcool, a água ficou de baixo do óleo, a camada de óleo atrapalhou no encontro do álcool com a água (Registro escrito do estudante E).

No diário de aplicação da tarefa, a professora textualiza que os estudantes:

[...] acharam que a água tinha ficado em baixo porque tinha tinta guache, então fizemos novamente sem tinta, aí então um aluno queria ver se nós colocássemos primeiro o óleo, então fizemos, e eles verificaram que a água passou pelo óleo e se posicionou abaixo. (Diário de aplicação da tarefa de modelagem, Prof. L, 2015).

Do exposto, percebe-se o movimento analítico dos estudantes para elaborar e comprovar, empiricamente, conjecturas acerca da disposição dos líquidos. Entende-se que o questionamento é o que impulsiona a pesquisa em sala de aula. Entretanto, a partir dele, torna-se necessária a construção de argumentos que extrapolem o senso comum e justifiquem a comprovação empírica, ou seja, a 
construção de novos argumentos pode iniciar com os conhecimentos cotidianos dos estudantes. É necessário, contudo, avançar e "pensar adiante do que já é conhecido, [...] criar novos modos de explicar e compreender as coisas" (MORAES, 2012, p. 97).

Nesse sentido, na fase de compreensão e explicitação, a professora L realizou outro experimento a fim de orientar os estudantes à compreensão do conceito de densidade e expressão de justificativas sobre a disposição dos líquidos, de modo que tal conceito fosse utilizado como argumento. Então, cada um dos três grupos, composto por quatro estudantes, foi responsável pela medição e registro da massa e volume de cada um dos líquidos e pela obtenção da razão entre estas grandezas, todas registradas em uma tabela. Para esse experimento, os estudantes utilizaram balança, béquer de vidro, água destilada, óleo de cozinha e álcool. Segundo a professora:

Esta parte demorou, eles se preocuparam em deixar o líquido bem direitinho na marca do béquer, a balança oscilava um pouco já que era de precisão, até por isso trabalhamos com volumes menores do que havia sido proposto primeiramente, utilizamos os volumes: $20 \mathrm{~mL}, 40 \mathrm{~mL}, 60 \mathrm{~mL} e$ 80mL. (Diáriode aplicação da tarefa de modelagem, Prof. L, 2015).

Em seguida, os estudantes realizaram o registro escrito referente a questionamentos com foco no significado da razão entre duas grandezas e resolução de problemas envolvendo proporcionalidade: a) Qual é a razão entre a massa e o volume que você calculou na tabela? O que indica o número que você encontrou? b) Que conclusão você tirou ao analisar os dados indicados na tabela? c) O que acontece, aproximadamente, com o valor da massa quando o volume é dobrado? E quando é triplicado? d) Que massa de água destilada deve ser medida na balança se forem colocados $20 \mathrm{ml}$ no copo de medidas? e) Que volume de água destilada deveria ser colocado no frasco para que a balança registrasse uma massa de $45 \mathrm{~g}$ nas condições do experimento? f) Qual deverá ser a massa correspondente a cada $\mathrm{ml}$ de água nas condições do experimento? De forma semelhante, foram propostas questões para o álcool e óleo.

No diário da professora $L$, ela destaca que os grupos apresentaram dificuldades para perceber a proximidade das razões calculadas e a variação da massa dos diferentes líquidos, o que demandou intervenções da professora. A estratégia dela para mediar o processo, a fim de que os estudantes compreendessem o conceito de densidade, foi propor a organização de uma única tabela contendo os valores obtidos pelos grupos. Ademais, os valores apresentados foram obtidos por meio da média aritmética daqueles encontrados pelos estudantes.

Tabela1 - Organização dos dados obtidos pelos estudantes no experimento.

\begin{tabular}{ccccccc}
\hline \multirow{2}{*}{ Volume (ml) } & \multicolumn{2}{c}{ Água $\left(1 \mathrm{~g} / \mathrm{cm}^{3}\right)$} & \multicolumn{2}{c}{ Óleo $\left(0,92 \mathrm{~g} / \mathrm{cm}^{3}\right)$} & \multicolumn{2}{c}{ Álcool $\left(0,78 \mathrm{~g} / \mathrm{cm}^{3}\right)$} \\
& Massa $(\mathbf{g})$ & $\frac{\boldsymbol{m}}{\boldsymbol{V}}$ & Massa $(\mathbf{g})$ & $\frac{\boldsymbol{m}}{\boldsymbol{V}}$ & Massa $(\mathbf{g})$ & $\frac{\boldsymbol{m}}{\boldsymbol{V}}$ \\
\hline $20 \mathrm{Ml}$ & $18,8 \mathrm{~g}$ & $0,94 \mathrm{~g} / \mathrm{mL}$ & $16,4 \mathrm{~g}$ & $0,82 \mathrm{~g} / \mathrm{mL}$ & $15,5 \mathrm{~g}$ & $0,77 \mathrm{~g} / \mathrm{mL}$ \\
$40 \mathrm{Ml}$ & $37,9 \mathrm{~g}$ & $0,95 \mathrm{~g} / \mathrm{mL}$ & $36,6 \mathrm{~g}$ & $0,92 \mathrm{~g} / \mathrm{mL}$ & $32,5 \mathrm{~g}$ & $0,81 \mathrm{~g} / \mathrm{mL}$ \\
$60 \mathrm{~mL}$ & $58,9 \mathrm{~g}$ & $0,98 \mathrm{~g} / \mathrm{mL}$ & $54,1 \mathrm{~g}$ & $0,90 \mathrm{~g} / \mathrm{mL}$ & $48,3 \mathrm{~g}$ & $0,80 \mathrm{~g} / \mathrm{mL}$ \\
$80 \mathrm{Ml}$ & $81 \mathrm{~g}$ & $1,01 \mathrm{~g} / \mathrm{mL}$ & $74 \mathrm{~g}$ & $0,92 \mathrm{~g} / \mathrm{mL}$ & $66,7 \mathrm{~g}$ & $0,83 \mathrm{~g} / \mathrm{mL}$ \\
\hline
\end{tabular}

Fonte: Diário de implementação da professora L (2015). 
As intervenções seguintes estavam voltadas para a orientação dos estudantes quanto à comparação dos valores que haviam obtido:

Hoje, conforme planejado, iniciei a aula solicitando que comparassem os valores com os quais completaram as tabelas. Para tanto, escrevi as tabelas no quadro sugerindo que eles comparassem detalhadamente os valores. (Diário da aplicação da tarefa de modelagem, Prof. L, 2015).

O fragmento evidencia que a professora pretendia que os estudantes comparassem e percebessem que, mesmo realizando o experimento com diferentes quantidades dos líquidos, a razão encontrada mantinha-se aproximadamente a mesma. A ideia de aproximação também foi tematizada no seu diário:

Expliquei que era um experimento e que por isso determinamos valores aproximados que podem comprovar por aproximação os dados que os cientistas definiram a partir de experimentos realizados com alta precisão. (Diário da aplicação da tarefa de modelagem, Prof. L, 2015).

Em relação ao questionamento sobre o significado dos valores encontrados, ela textualiza:

[...] a única frase que saiu é que "a água teve maior valor porque é mais pesada, tem maior massa”. (Diário da aplicação da tarefa de modelagem, Prof. L, 2015).

Ainda, após a realização dos experimentos e obtenção numérica dos dados apresentados na Tabela 1, a professora expressa que os estudantes continuavam a apresentar dúvidas a respeito da disposição obtida:

[...] alguns alunos disseram várias vezes "profe, mas parece que não pode, o óleo é mais grosso tinha que ser mais pesado", outro "é profe o óleo é grudento, parece que ele que tinha que segurar a água”. (Diário de aplicação da tarefa de modelagem, Prof. L, 2015).

A partir de tais registros escritos pode-se perceber que os estudantes confundem, sem consciência dos conceitos, a densidade e a viscosidade. No diário de aplicação da professora $L$ não há evidências se houveram discussões sobre tais conceitos.

Na fase de significação e expressão, após a realização das situações-problema envolvendo o cálculo de razão e noções de proporcionalidade, os estudantes foram questionados: Como faríamos para calcular a densidade da gasolina? Poderíamos escrever uma fórmula para o cálculo da densidade?

[...] para a questão: como você faria para calcular a densidade da gasolina? Responderam: "da mesma forma que calculamos a densidade da água, do óleo e do álcool, determinamos um volume e verificamos a massa desse volume e calculamos a razão entre massa e volume". (Diário de aplicação da tarefa de modelagem, Prof. L, 2015).

Neste momento devolveram a seguinte pergunta: "professora não entendi, como assim fórmula?" Então eu disse: "se alguém perguntasse para vocês como calculamos a densidade de um líquido, como responderiam?" Então vários disseram: "dividindo a massa pelo volume". (Diário de aplicação da tarefa de modelagem, Prof. L, 2015). 
Do exposto em tais excertos, observa-se que os estudantes expressaram, verbalmente, o modelo para o cálculo da densidade. A retomada dos questionamentos pela professora $L$ proporciona condições de perceber, no registro escrito dos estudantes, que eles textualizaram suas explicações, trazendo o conceito de densidade e utilizando-o para justificar suas respostas.

Porque a densidade da água é maior que a do petróleo. (Registro escrito do Estudante E).

Porque o petróleo é menos denso que a água, por isso ele subiu pra cima. (Registro escrito do Estudante F).

Eles ficam separados porque um é menos denso que o outro. (Registro escrito do Estudante W).

Por causa da densidade, o petróleo é mais leve que a água. (Registro escrito do Estudante M).

As considerações dos estudantes não expressam apenas ideias do senso comum, mas estão ancoradas no conceito que foi por eles (re)construído constituindo-se, portanto, como novo conhecimento aos estudantes.

Ao final da atividade, a professora $L$ expressa uma avaliação a respeito da realização da tarefa de Modelagem na Educação (realizada por ela) com os estudantes, o que pode ser observado no seguinte excerto:

A aula foi atrativa, prazerosa para mim e meus alunos, percebi que estavam envolvidos com a atividade, estavam curiosos, motivados... saíram da aula felizes e me disseram: "profe tínhamos que ter mais aulas assim". Me senti bem, foi gostoso ver o interesse dos alunos que comentaram com outros professores a atividade [...] (Diário de aplicação da tarefa de modelagem, Prof. L, 2015).

Destaca-se que, para a professora $\mathrm{L}$, a avaliação da realização da tarefa de Modelagem com os estudantes foi positiva. Seus escritos a respeito evidenciam que a tarefa proposta promoveu o envolvimento dos estudantes e despertou a curiosidade deles, mudando o foco da sala de aula da figura do professor para a figura do estudante e deixando surgir, no professor, a sua função orientadora e mediadora.

Identificou-se, no diário da professora, que ela também planeja a realização de outras tarefas de Modelagem com os estudantes. Entretanto, percebe-se que as prescrições regulam o seu trabalho na sala de aula, isto é, ao mesmo tempo em que existe o desejo de implementar mais tarefas de modelagem, ela se vê presa ao cronograma estabelecido para o desenvolvimento dos conteúdos programáticos e ações rotineiras de sala de aula, como a realização das avaliações com os estudantes.

Ao finalizar a atividade me sinto muito feliz [...] fizeram comparações, sabe estou com vontade de aplicar a atividade das caixinhas/embalagens... mas não posso fugir do foco, temos o relato desta atividade para desenvolver até o final do mês e não posso esquecer que este mês é encerramento do trimestre, temos avaliações para serem desenvolvidas. O que sei é que pretendo dentro do possível realizar outras práticas pedagógicas, pois me realizei vendo a alegria e o envolvimento dos meus alunos. (Diário de aplicação da tarefa de modelagem, Prof. L, 2015). 
Em tal registro, realça-se que a professora, ao planejar e implementar a tarefa, vislumbra outras possibilidades. Por meio do diálogo que estabelece com esta nova realidade, a professora altera o seu ponto de vista, cria novos marcos de referência e novas formas e perspectivas de perceber e reagir, o que caracteriza, segundo Gómez (1995), uma atitude para um ensino reflexivo.

\section{ALGUMAS CONSIDERAÇÕES}

O objetivo deste artigo foi apresentar o relato da experiência do desenvolvimento de uma tarefa de Modelagem (Matemática) realizada com um grupo de professores de Matemática e sua projeção para a sala de aula a partir dos reflexos na e da formação continuada. O vivenciar o processo de MM na formação continuada desencadeou novas tarefas investigativas e favoreceu a projeção dessa prática para sala de aula como forma de explorar dois conceitos importantes da Matemática: razão e proporcionalidade, por meio do conceito de densidade. Sendo assim, a projeção de tarefas de Modelagem na Educação por parte da professora participante é oriunda da reflexão na formação continuada, indicando reflexos da proposta oriunda do projeto dessa universidade.

A partir do diário de aplicação da tarefa de Modelagem da Prof. $L$ e dos registros escritos dos seus estudantes, pode-se inferir que durante a realização da tarefa os estudantes (re)elaboraram as representações textualizadas sobre a disposição dos líquidos e significaram o conceito de densidade, utilizando-o em suas argumentações. Entretanto, esse conceito não é utilizado para resolver os problemas propostos envolvendo razão e proporcionalidade. Pode ser que, se a tarefa for conduzida por outro professor, os resultados obtidos sejam diferentes, pois a condução do processo é muito importante durante o desenvolvimento das tarefas de modelagem. Este último fator se constitui em uma das limitações do estudo. Assim, há de se continuar a refletir sobre o fazer docente na formação continuada e discutir com os professores maneiras de mediação para que os propósitos sejam atingidos.

No que diz respeito ao planejamento e implementação da tarefa com estudantes da Educação Básica, a avaliação da Prof. L é positiva e, em decorrência disso, ela planeja o desenvolvimento de outras práticas de Modelagem com os estudantes. Todavia, embora ela realize projeções de inserir outras tarefas de modelagem, não se tem garantias de que o faça, visto que o trabalho do professor não se desenvolve apenas no contexto específico de sala de aula e não se limita apenas a 'dar aula'. O entrar em tal ambiente exige que o professor planeje sua ação e o faça considerando as suas condições de trabalho, entre elas: tempo para planejamento e desenvolvimento das aulas, número de estudantes, número de turmas e recursos disponíveis. Assim, há de se discutir mais na formação continuada a respeito das prescrições que envolvem a prática docente e sua relação com o currículo.

Ademais, o agir docente está condicionado a uma série de orientações (prescrições) provenientes de diferentes instâncias educacionais, as quais desencadeiam e são constitutivas da sua prática docente (como os conteúdos programáticos apresentados nos planos de ensino) e também aos motivos, intenções e capacidades do professor ao considerar a gestão da aula e seu percurso, as 
expectativas e os objetivos predefinidos pela instituição escolar e as características e reações efetivas dos estudantes.

Diante disso, reforça-se o estudo da MM na Educação Matemática em espaços de formação (inicial e continuada), proporcionando ao professor vivenciar as seguintes dimensões: i) aprender por meio da Modelagem; ii) aprender sobre Modelagem; iii) adaptar o processo para o ensino de Matemática. Contudo, não basta promover um curso de formação continuada sem analisar as influências da formação na ação docente e de que forma a participação na formação continuada potencializa a (re)configuração do trabalho do professor e suas representações sobre o ensino e aprendizagem de Matemática. Isso se torna importante não apenas para compreender se há (re)configurações no trabalho do professor e nas suas concepções de ensino, mas também para nortear e redimensionar as ações de formação continuada com Modelagem para professores da Educação Básica.

\section{REFERÊNCIAS}

1. ALARCÃO, I. Professoresreflexivosemumaescolareflexiva. 7. ed. São Paulo: Cortez, 2010.

Reflexão e Ação [ISSN 1982-9949]. Santa Cruz do Sul, v. 28, n. 1, p. 235-253, jan./abr. 2020. 
2. BARBOSA, J. C. As relações dos professores com a Modelagem Matemática. In: ENCONTRO NACIONAL DE EDUCAÇÃO MATEMÁTICA, 8, 2004, Recife. Anais...Recife: SBEM, 2004. 1 CDROM.

3. BIEMBENGUT, M. S. Modelagem Matemática no Ensino Fundamental. Blumenau: EdiFurb, 2014.

4. BIEMBENGUT, M.S.; HEIN, N. Modelagem Matemática no Ensino. 3 ed. São Paulo: Contexto, 2003.

5. BISOGNIN, E.; BISOGNIN, V. Percepções de professores sobre o uso da Modelagem Matemática em sala de aula. Bolema, v. 26, n. 43, p.277-297. 2012.http://dx.doi.org/10.1590/S0103$636 \times 2012000300013$

6. BONOTTO, D. L.; LARA, I. C. M. Modelagem Matemática e formação continuada de professores: um mapeamento teórico. In: CIEM, VI, 2013, Canoas Anais... Canoas: Ulbra, 2013.

7. CHAVES, M. I. A. Percepções de professores sobre repercussões de suas experiências com Modelagem Matemática.01/09/2012. 134 f. Tese (Doutorado em Educação em Ciências e Matemática). Universidade Federal Do Pará. Biblioteca Depositária: Biblioteca Setorial do IEMCI UFPA.

8. CONTRERAS. J. Autonomia de professores. São Paulo: Cortez, 2002.

9. DIAS, M. R. Uma experiência com Modelagem Matemática na formação continuada de professores. 2005. 121p. Dissertação (Mestrado em Ensino de Ciências e Educação Matemática), Universidade Estadual de Londrina, Londrina-PR, 2005.

GÓMEZ, A. P. O pensamento prático do professor - a formação do professor como profissional reflexivo. In: NÓVOA, A. (Org.). Os professores e a sua formação. Lisboa: Dom Quixote, 1995. p. 93-115.

IMBERNÓN, F. Formação Continuada de Professores. Porto Alegre: Artmed, 2010.

LUNA, A. V. A. A modelagem matemática na formação continuada e a recontextualização pedagógica desse ambiente em salas de aula. Tese (Doutorado em Ensino, Filosofia e História das Ciências) - Universidade Federal da Bahia, Salvador, 2012. 
13. MORAES, R. Educar pela pesquisa: exercício de aprender a aprender. In: MORAES, R.; LIMA, V.M.R. (Orgs.). Pesquisa em sala de aula: tendência para a educação em novos tempos. 3. ed. Porto Alegre: EDIPUCRS, 2012.

14. NÓVOA, A. Os professores e a sua formação. Tradução de Graça Cunha, Cândida Hespanha, Conceição Afonso e José António Souza Tavares. 2. ed. Lisboa: Instituto Inovação Educacional, 1995.

15. OLIVEIRA, A.M.P.Modelagem Matemática e as tensões nos discursos dos professores. 2010. 199f. Tese (Doutorado em Ensino, Filosofia e História das Ciências), Universidade Estadual de Feira de Santana, Salvador, 2010.

PORLÁN, R.; MARTÍN, J. El diario del profesor: un recurso para investigación en el aula. Díada: Sevilla, 1997.

SCHELLER, M; BONOTTO, D.; BIEMBENGUT, M. S. Formação continuada e Modelagem: percepções de professores. Educação Matemática em Revista. Ano 20, n. 46, p. 16-24, set. 2015. Disponível em: <http://www.sbem.com.br/revista/index.php/emr/article/view/499/pdf>. Acesso em: 21 fev. 2017.

SCHÖN, D. Educando o profissional reflexivo: um novo design para o ensino e aprendizagem. Tradução de Roberto Cataldo Costa. Porto Alegre: Artmed, 2000. professores e a sua formação. Lisboa: Dom Quixote, 1995. p. 93-115.

SILVEIRA, E.; CALDEIRA, A. D. Modelagem na sala de aula: resistências e obstáculos. Bolema, Rio Claro (SP), v. 26, n. 43, p. 249-275, ago. 2012.http://dx.doi.org/10.1590/S0103-636X2012000300013. ed. São Paulo: Martins Fontes, 2008 [primeira edição, 1987]. profissional. Tradução de Ernani Rosa. Porto Alegre: Artmed, 2004.

\section{Danusa de Lara Bonotto}

Doutora em Educação em Ciências e Matemática pela PUCRS (2017), mestre em Matemática pela Universidade Federal do Rio Grande do Sul (2000) e graduada em Matemática Licenciatura Plena pela Universidade Federal de Santa Maria (1997). Atuou como docente nos níveis de ensino fundamental e 
médio e atualmente é professora no ensino superior e atua no Programa de Pós-Graduação em Ensino de Ciências na Universidade Federal da Fronteira Sul - Campus Cerro Largo/RS. Possui experiência na área de Matemática e Educação Matemática com pesquisa principalmente nos seguintes temas: ensino-aprendizagem de Matemática na educação básica e no ensino superior e formação inicial e continuada de professores.

\section{Morgana Scheller}

Doutora em Educação em Ciências e Matemática pela PUCRS. Realizou também no período de doutoramento, estudos na Universidade de Salamanca (2015/2016) na modalidade de doutorado sanduíche em Didáctica de las Matemáticas. Possui também: (i) mestrado em Ensino de Matemática pela Universidade Federal do Rio Grande do Sul - UFRGS (2009); (ii) especialização em Metodologia do Ensino de Matemática pela Universidade para o Desenvolvimento do Alto Vale do Itajaí (2002); (iii) especialização em Gestão Escolar pela UDESC (2002), (iv) graduação em Matemática pela Fundação Universidade Regional de Blumenau (1996); e (v) graduação em Pedagogia pela UNINTER (2017). Atualmente é docente do Instituto Federal de Educação, Ciência e Tecnologia Catarinense - Campus Rio do Sul, atuando nas disciplinas de Matemática para o Ensino Integrado e na formação de professores de matemática.Tem experiência na área de Educação Matemática, Formação de professores, com ênfase em Matemática, Formação continuação de professores das Feiras de Matemática, Projetos de Iniciação Científica, Laboratório de Ensino e Aprendizagem de Matemática e Estágio Supervisionado.

\section{Valderez Marina do Rosário Lima}

Possui graduação em Licenciatura em Ciências Primeiro Grau pela Pontifícia Universidade Católica do Rio Grande do Sul (1977), graduação em Licenciatura em Ciências Habilitação em Biologia pela Pontifícia Universidade Católica do Rio Grande do Sul (1980), mestrado em Educação pela Pontifícia Universidade Católica do Rio Grande do Sul (1998) e doutorado em Educação pela Pontifícia Universidade Católica do Rio Grande do Sul (2003). Atualmente é professora adjunta da Pontifícia Universidade Católica do Rio Grande do Sul, com atividades docentes na Faculdade de Educação e na Faculdade de Biociências. É professora permanente dos Programas de Pós-Graduação em Educação (Faculdade de Educação) e em Educação em Ciências e Matemática (Faculdade de Física). Tem experiência na área de Educação, com ênfase em Educação em Ciências, desenvolvendo pesquisas nos seguintes temas: educar pela pesquisa, ciências, feiras e clubes de Ciências, educação e avaliação, formação e continuada de professores.

\section{Como citar este documento}

BONOTTO, Danusa de Lara; SCHELLER, Morgana; LIMA, Valderez Marina do Rosário. Modelagem (matemática) e modelagem na educação: reflexos na e da formação continuada. Reflexão e Ação, Santa Cruz do Sul, v. 28, n. 1, jan. 2020. ISSN 1982-9949. Disponível em: 
<https://online.unisc.br/seer/index.php/reflex/article/view/9870>.

Acesso

em:

doi:https://doi.org/10.17058/rea.v28i1.9870.

Reflexão e Ação [ISSN 1982-9949]. Santa Cruz do Sul, v. 28, n. 1, p. 235-253, jan./abr. 2020.

https://online.unisc.br/seer/index.php/reflex/index 